\title{
Experimental identification of the transition from elasticity to inelasticity from ultrasonic attenuation analyses
}

\author{
Auke Barnhoorn ${ }^{1}$, Jeroen Verheij ${ }^{1}$, Marcel Frehner ${ }^{2}$, Alimzhan Zhubayev ${ }^{3}$, and Maartje Houben ${ }^{4}$
}

\begin{abstract}
The transition from recoverable elastic to permanent inelastic deformation is marked by the onset of fracturing in the brittle field. Detection of this transition in materials is crucial to predict imminent failure/fracturing. We have used an ultrasonic pulse transmission method to record the change in waveform across this transition during fracturing experiments. The transition from elastic to inelastic deformation coincides with a minimum in ultrasonic attenuation (i.e., maximum wave amplitude). Prior to this attenuation minimum, the existing microfractures close. After this minimum, new microfractures form and attenuation increases until peak stress conditions, at which point, larger fractures form leading to complete sample failure. In our experiments, velocity changes are not sensitive enough to be indicative for the transition from elastic to inelastic deformation. Analysis of attenuation, not velocity, may thus detect imminent failure in materials. Our results may help detect fracturing in borehole casings or the near-wellbore area, or they may help predict imminent release of energy by seismic rupture.
\end{abstract}

\section{INTRODUCTION}

The presence of fractures, either natural or induced, has a strong control on fluid flow in the earth's crust and becomes increasingly important for oil and gas exploration, geothermal energy, and other geologic near-surface applications (e.g., Curtis, 2002; Cramer, 2008). The production of earth resources is shifting from increasingly scarce conventional resources (traditional highporosity, high-permeability rocks) toward abundant, but more difficult to produce, unconventional reservoirs that contain natural or man-made fracture networks (e.g., fractured carbonates, shale or tight sandstone reservoirs, and deep geothermal reservoirs). In addition, the formation of fractures or the reactivation of faults or fractures due to high fluid pressure has caused induced seismic events that are of great concern to society (Haering et al., 2008). Increasing our understanding of how and when fracture networks are formed and what characteristics of fracture networks we can detect (e.g., using seismic measurement techniques) is thus vital for maintaining sufficient and safe exploitation of earth's resources in the coming decades.

Seismic waves are significantly affected by the presence of fractures and faults. Fractures and fracture networks can cause reflection and/or diffraction of seismic waves (Groenenboom and Falk, 2000; Ionov, 2007), may lead to seismic anisotropy (Maultzsch et al., 2003; Zhong et al., 2014), and even give rise to additional seismic wave modes (Frehner and Schmalholz, 2010; Maksimov et al., 2011; Frehner, 2014; Shih and Frehner, 2016). Elastic wave velocities are generally reduced by the presence of open microcracks and fractures and during an increase in fracture density (Peacock et al., 1994; Sayers and Kachanov, 1995; Saenger and Shapiro, 2002; Schubnel and Guéguen, 2003; Sarout et al., 2017). Similar to changes in velocities during fracturing and compaction (e.g., Fortin et al., 2006, 2007; Eslami et al., 2010; Nicolas et al. 2016, 2017; Bonnelye et al., 2017), elastic moduli can also be affected by the increase in damage in a rock body (e.g., Sarout and Guéguen, 2007; Heap et al., 2010). Therefore, spatial changes in elastic wave velocity may reveal fracture-related rock properties (e.g., increase or decrease in fracture density). Temporal changes in wave velocity (Peng and Ben-Zion, 2006) may be used

\footnotetext{
Manuscript received by the Editor 11 August 2017; revised manuscript received 5 January 2018; published ahead of production 24 April 2018; published online 25 June 2018.

${ }^{1}$ Delft University of Technology, Department of Geoscience and Engineering, Delft, The Netherlands. E-mail: auke.barnhoorn@tudelft.nl; verheij.jeroen@ gmail.com.

${ }^{2}$ Geological Institute, ETH Zurich, Zurich, Switzerland. E-mail: marcel.frehner@erdw.ethz.ch.

${ }^{3}$ Formerly Delft University of Technology, Department of Geoscience and Engineering, Delft, The Netherlands; presently NAM-Shell Projects and Technology, Assen, The Netherlands. E-mail: zhubayev@gmail.com.

${ }^{4}$ Utrecht University, Faculty of Geosciences, Utrecht, The Netherlands. E-mail: m.e.houben@uu.nl.

(C) 2018 Society of Exploration Geophysicists. All rights reserved.
} 
to monitor the progressive formation of fractures over time, e.g., in near-well-bore environments (e.g., Charléty et al., 2006) or from 4D seismic (e.g., Alassi et al., 2010) provided that the wavelength of the seismic signal is sufficiently sensitive to the fracture dimensions. In addition to changes in velocity, a decrease in amplitude (i.e., attenuation) of the reflected or transmitted elastic waves and the coda can also reveal changes in fracture properties (Herriaz and Espinosa, 1987; Snieder et al., 2002). Fracturerelated attenuation can be due to increased frictional sliding on fracture surfaces and grain boundaries (Mavko, 1979), viscous fluids in the fractures (Rubino et al., 2013, 2015; Quintal et al., 2014), or scattering at the fractures (Main et al., 1990). As wave velocities often decrease when they encounter fractures, the amplitude of the seismic wave can also decrease (increase in attenuation) due to the presence of fractures. Because of the high sensitivity of the wave amplitude to the presence of fractures amplitude/attenuation analysis is in addition to velocity analyses potentially another promising method for fracture detection, analysis, and interpretation.

Attenuation of ultrasonic waves (defined here as P- and S-waves) with increasing stress (isotropic and deviatoric) and strain has been measured in laboratory studies on different rock types. Such experimental studies generally show a decrease in attenuation with increasing stress applied to the rock samples (Toksoz et al., 1979; Winkler and Nur, 1979; Guo et al., 2009; Wei and Fu, 2014; Zhubayev et al., 2016). This attenuation decrease is generally attributed to pore or crack closure (Winkler and Nur, 1979). Open microcracks present prior to the experiment cause relatively high attenuation compared with a medium without any microcracks. Progressive closure of microcracks causes a decrease in attenuation up to a level at which a further increase in stress results in no additional attenuation reduction of the ultrasonic waves (Guo et al., 2009; Zhubayev et al., 2016). The stress-dependent attenuation reported in these studies occurs within the elastic deformation field, i.e., below the yield stress levels, and thus no new cracks/microfractures have been formed in these experiments.

At deviatoric stress levels just above the yield strength and at temperature/pressure conditions in which brittle deformation is dominant, the first new microfractures start to form (Barnhoorn et al., 2010). With increasing stress, fractures nucleate, grow, and coalesce until a connected network of fractures has developed, at which point, macroscopic failure of the rock sample occurs (Kranz, 1983; Paterson and Wong, 2005). The formation of new fractures beyond the elastic limit generally decreases the wave velocity (Hadley, 1976; Granryd et al. 1983; Yukutake, 1989; Sayers, 2002a; Fortin et al., 2007; Eslami et al., 2010; Nicolas et al. 2016, 2017; Bonnelye et al., 2017). However, the change in attenuation during the fracturing process beyond the elastic limit has not yet been investigated extensively (Couvreur et al., 2001; Goodfellow et al., 2015); it is the main objective of this study. In analogy to fracture closure, where attenuation generally decreases (Zhubayev et al., 2016), fracture formation should cause an increase in attenuation. Indeed, Couvreur et al. (2001) measure in a limestone sample a decrease, stabilization, and increase of attenuation with increasing stress, and they relate this effect to pore closure and appearance of cracks. Here, we report an experimental study on shale, limestone, and sandstone samples, in which $\mathrm{P}$ - and S-wave velocities and attenuation were measured during an increase in stress and fracture formation until complete failure of the rock samples.

\section{MATERIALS AND METHODS}

\section{Rock-sample material}

We subjected a total of 13 rock samples to unconfined fracturing experiments and simultaneously recorded the ultrasonic P- or $\mathrm{S}$-wave transmission waveforms. These were six Whitby shale/ mudstone samples, four Bentheimer sandstone samples, and three Indiana limestone samples.

We collected the Whitby shale samples from outcrops along the coast at Runswick Bay (Yorkshire, UK). They consist of finely $(\mathrm{mm})$ laminated shale layers with some quartz and a clay matrix. The Whitby shale is of Lower Jurassic age and is the lateral equivalent of the Posidonia shale in northern Europe (Littke et al., 1991; Powell, 2010; Ghadeer and Macquaker, 2012). The Whitby shale has generally a low porosity $(<7 \%)$ and is relatively clay-rich and quartz-poor (Houben et al., 2016), and it has an ultrasonic P- and S-wave velocity anisotropies of approximately 30\% (Zhubayev et al., 2016; Douma et al., 2017). The porosity mainly occurs in the clay matrix and is generally unconnected in $2 \mathrm{D}$ and even not always in $3 \mathrm{D}$ preventing fluid flow through the samples. The permeability depends on the confining pressure and is in the order of $1 \times 10^{-20} \mathrm{~m}^{2}$ (Houben et al., 2017).

The Bentheimer sandstone is a Lower Cretaceous pure coarsegrained sandstone outcropping in Bentheim (Germany) with porosity between $21 \%$ and $27 \%$ and permeability between $0.5 \times 10^{-12}$ and $3 \times 10^{-12} \mathrm{~m}^{2}$ (Peksa et al., 2015).

Indiana limestone is a pure calcite-cemented grainstone of Mississippian age from the United States. It contains some fossil fragments and oolites (Hart and Wang, 1995), has porosity of $19 \%$, and permeability of $70 \times 10^{-15} \mathrm{~m}^{2}$.

All cylindrical samples that we cored (Bentheimer sandstone and Indiana limestone) have a diameter of $40 \pm 0.5 \mathrm{~mm}$ and a length of $32 \pm 0.5 \mathrm{~mm}$. The Whitby shale was too fragile to core, and we polished the samples manually into cylindrical shapes (Zhubayev et al., 2016) with a diameter of $40 \pm 0.5 \mathrm{~mm}$ and lengths ranging from $27 \pm 0.5$ to $41 \pm 0.5 \mathrm{~mm}$. Due to the difficulty of preparing long shale samples because of its fragile nature, the length/diameter ratio of the samples is smaller than the ideal 2:1 ratio (Paterson and Wong, 2005). This probably caused some stress-shadowing effect in the samples that in turn affected the strength values somewhat and caused fractures to preferentially start forming in the center of the sample (at the highest stress regions) instead of randomly positioned in the material.

\section{Laboratory methods}

To simultaneously study fracturing and elastic wave propagation in rocks at elevated stress conditions, we integrated an ultrasonic setup within a high-stress uniaxial deformation system. In this combined setup, it is possible to measure $\mathrm{P}$ - or $\mathrm{S}$-wave velocities while the sample is put under stress uniaxially up to failure (Figure 1). The uniaxial deformation setup can apply a maximum force of $500 \mathrm{kN}$, which corresponds to stress of approximately $400 \mathrm{MPa}$ for cylindrical samples with a diameter of $40 \mathrm{~mm}$. We placed the oven-dried at $70^{\circ} \mathrm{C}$ Bentheimer sandstone and Indiana limestone or as-received Whitby shale rock samples between two aluminum buffers (Zhubayev et al., 2016), and ultrasonic P- or S-wave transducers (one transmitter and one receiver) were coupled to each of the buffers with a viscous gel. The vertical stress applied to the system ensured 
coupling at the buffer-sample interface. We uniaxially shortened the sample at a constant strain rate (approximately $1-2.5 \times 10^{-4} \mathrm{~s}^{-1}$ ) in the absence of any confining pressure, at room temperature. We recorded the uniaxial stress with a load cell and the vertical displacement applied to the sample with two diametrically opposed linear variable displacement transducers. The average strain of the sample is obtained by dividing the displacement by the initial length of the sample. For the shale samples, vertical stress was applied perpendicular to the shale layering. After a certain incremental change in strain or stress, we halted the experiment and recorded the ultrasonic P- or S-waveform transmitted through the sample.

During the ultrasonic measurement, we held the strain constant by stopping the axial actuator. Consequently, the stress relaxed slightly in the inelastic regime during the measurement (maximum stress drop $<1 \mathrm{MPa}$ ). Using this procedure multiple times during a single fracturing experiment, we typically performed tens of ultrasonic measurements (Figure 2) across the complete deformation range (in the elastic part, in the strain hardening part, during microfracturing, and up to complete failure of the sample; Figure 3). As a reference, we duplicated every experiment across the complete range of stress values on an aluminum sample with exactly the same dimensions (length and diameter) as each rock sample. To measure ultrasonic velocity and attenuation, we used compressional $(\mathrm{P})$ and shear $(\mathrm{S})$ source and receiver transducers with a central frequency of $1 \mathrm{MHz}$. The polarization of the shear source and receiver transducers was always aligned. We corrected the velocity and attenuation values for the shortening of the aluminum and rock samples due to the applied stress.

We used the laboratory method described by Toksoz et al. (1979) to determine the ultrasonic attenuation (i.e., inverse of the quality factor $Q$ ), as is also described in detail in Zhubayev et al. (2016). Assuming constant $Q$, the spectral ratio is

$$
\ln \left(\frac{A_{1}}{A_{2}}\right)=\left(\beta_{2}-\beta_{1}\right) x f+\ln \left(\frac{G_{1}}{G_{2}}\right),
$$

where $A_{i}$ is the Fourier amplitude, $f$ is the frequency, $x$ is the propagation distance, and $G_{i}$ is the scaling factor due to spherical spreading, which is independent of frequency. Subscripts $i=1$ and 2 refer to the reference aluminum sample and the rock sample (shale, limestone, or sandstone), respectively. Finally, $\beta_{i}$ is related to the quality factor $Q$ by

$$
Q_{i}=\frac{\pi}{\beta_{i} V^{\prime}}
$$

where $V$ is the ultrasonic P- or S-wave velocity, depending on the performed experiment. Source and receiver functions are considered to be the same. Due to very low attenuation $(Q \approx$ 150,000; Zemanek and Rudnick, 1961) in aluminum, $\beta_{1}$ in equation 1 can be assumed to be zero. Only the response of transmitted $\mathrm{P}$ - and S-wave effects is taken into account, and we used a relatively short time window so that we capture only the first-arrival wavelet of the full $\mathrm{P}$ - or S-waveform to calculate the spectra for the rock sample and for aluminum to be used in equation 1 . The slope of the best-fit linear regression in the range around the central frequency of $1 \mathrm{MHz}$ is then used to calculate the attenuation $\left(Q^{-1}\right)$ of the rock sample (Toksoz et al., 1979). The attenuation $Q^{-1}$ is small when the wave amplitude in Figures 2 and 3 is large, and it is large when the wave amplitude is small. Similarly, as in Zhubayev et al. (2016), absolute errors in the velocity and attenuation were estimated to be at maximum approximately $3 \%$ and $12 \%$, respectively.

To quantify the transition from elastic to inelastic deformation, we calculated the gradient of the stress-strain curves (Figure 4). At low stresses, the increase in gradient is caused by settling of the machine or closure of preexisting microcracks. This interval is followed by elastic deformation characterized by a linear

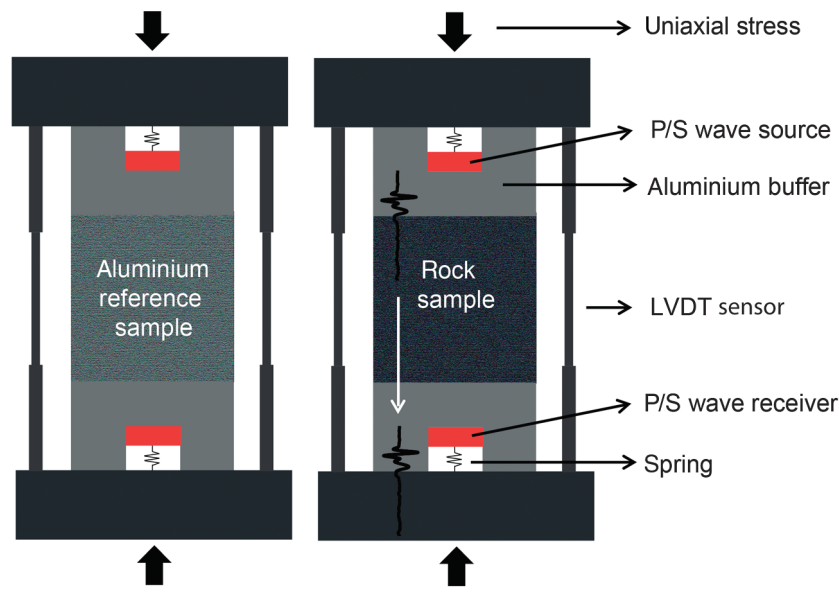

Figure 1. Experimental setup used to measure axial strain, P- and $\mathrm{S}$-wave velocities, and attenuation at different uniaxial stress conditions for rock samples (Whitby shale, Bentheimer sandstone, and Indiana limestone) and aluminum reference samples of exactly the same length and diameter as the rock samples.

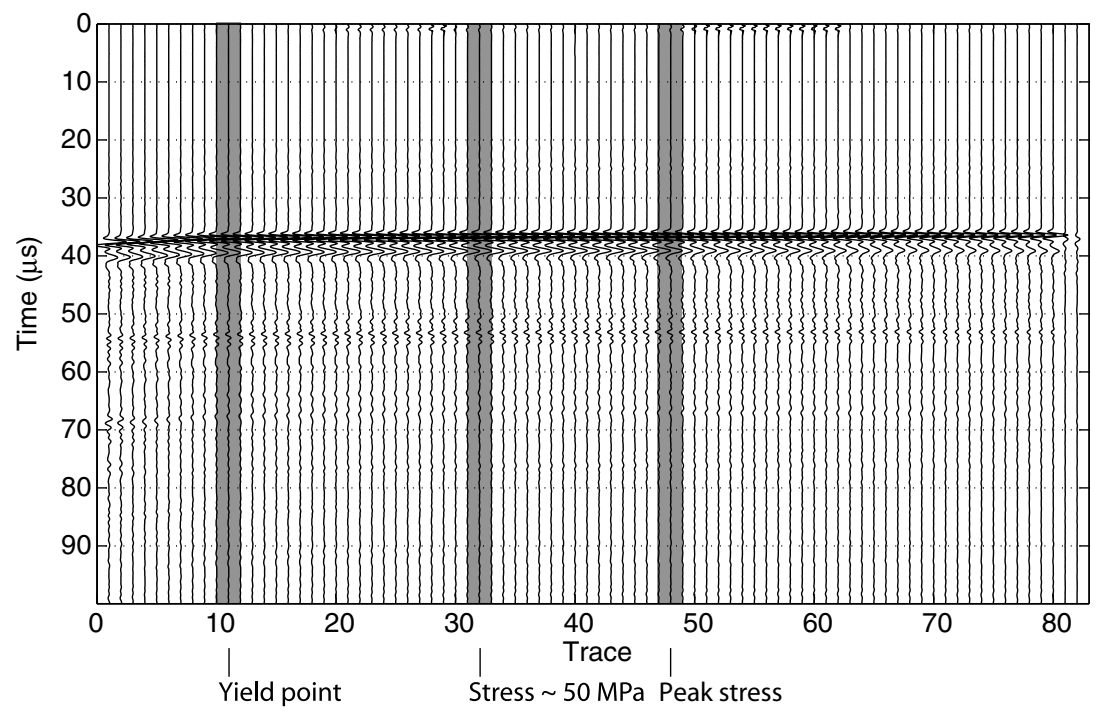

Figure 2. All $82 \mathrm{~S}$-wave traces recorded during the uniaxial unconfined compression experiment of Whitby shale sample 47B. The deformation experiment was halted 82 times to record an S-wave signal transmitted through the sample (shale layering perpendicular to the wave-propagation direction). Traces related to the yield point, a stress of $50 \mathrm{MPa}$, and peak stress conditions are highlighted. 
stress-strain relationship and hence a constant gradient value. With increasing deformation, we define the transition from elastic to inelastic behavior as the point at which the stress-strain gradient decreases again (Figure 4b). crease. Only the larger fractures affect the trend in velocity, and the steady increase in velocity with strain is halted and eventually reversed (e.g., Lockner et al., 1977). The transition from elastic to inelastic deformation can thus not always be deciphered from the velocity measurements.

We also recorded the amplitude of the waveforms during the fracturing experiment. Wave amplitudes can be very sensitive to
After initial setting of the machine at very low stresses, the stress-strain curves are linear (constant gradient in Figure 4a) describing the elastic (reversible) part of the deformation. After that, the gradient decreases indicating the transition from elastic to inelastic deformation (Figure 4). In the inelastic regime, the first brittle microfractures start to form (e.g., Barnhoorn et al., 2010). However, only at peak stress conditions do the first macroscopic fractures and connected networks (Barnhoorn et al., 2010) form, which express themselves by minor stress drops in the stress-strain curve (Figure 4a). With increasing strain, the sample eventually fails catastrophically, which is indicated by a final and significant stress drop (Figure 4a). In addition, this coincides with the release of large amounts of audible energy in the laboratory.

The recorded ultrasonic data sets (Figure $4 \mathrm{c}$ and $4 \mathrm{~d}$ for $\mathrm{S}$-wave measurements on a Whitby shale sample) show that the velocity continues to increase from the onset of the experiment across the transition from elastic to inelastic deformation. This increase in velocity is caused by the closure of microcracks preexisting in the sample (Walsh, 1965). This behavior is typical for velocity measurements under stress (e.g., Hadley, 1976; Yukutake, 1989; Mavko et al., 1995; Sayers, 2002b; Stanchits et al., 2006). Only at around peak stress conditions, when the first larger connected fractures form, is the continuous increase in velocity halted. The earlier formation of microfractures, here, does not contribute to a change in the trend of velocity in- a)
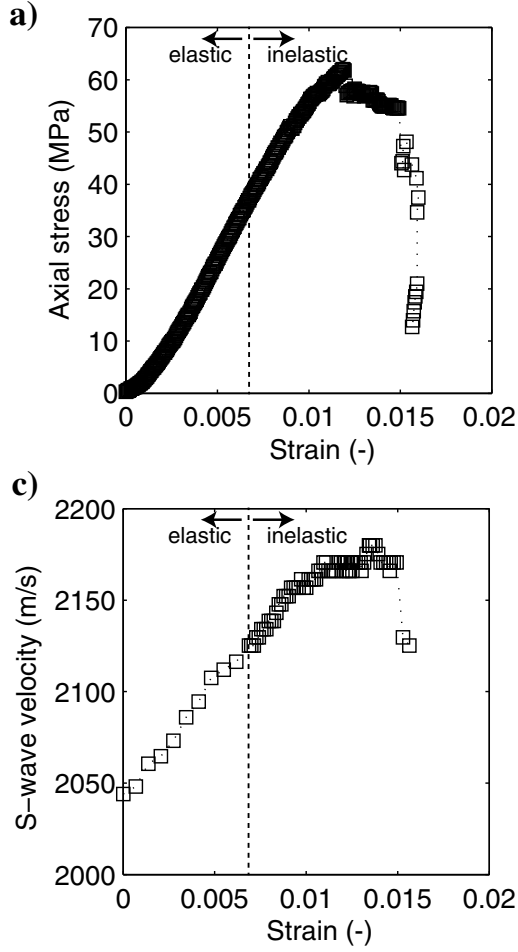

b)

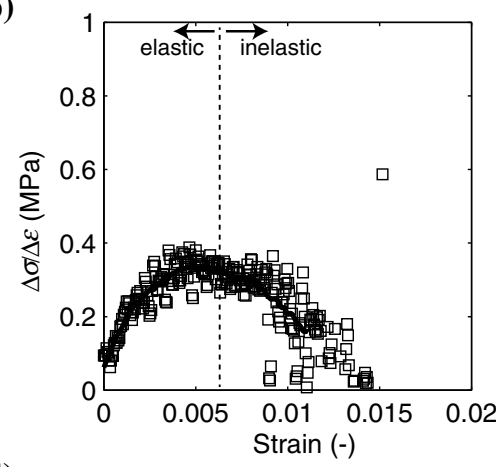

d)

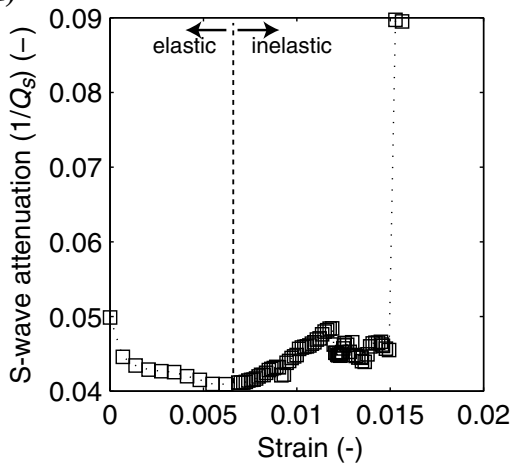

Figure 4. (a) Axial stress-strain diagram for Whitby shale sample 47B. (b) Gradient of the stress-strain data shown in (a). The solid line represents a smoothed average of the gradient data. After an initial increase, the gradient remains relatively constant (elastic regime). The transition from a constant gradient to a decrease in gradient represents the transition from elastic to inelastic deformation behavior. Accompanying measurements of (c) S-wave velocity with strain and (d) S-wave attenuation with strain. The strain at which the transition from elastic to inelastic deformation behavior occurs is indicated with the dashed vertical line.
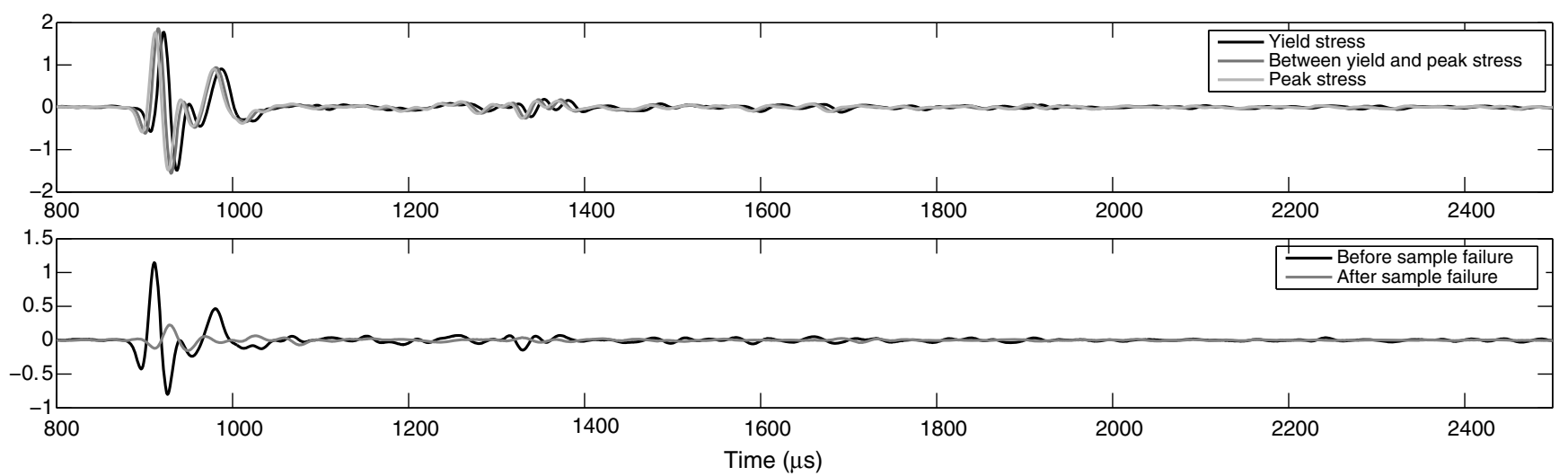

Figure 3. Comparison of P-wave traces in Figure 2 at (a) yield stress, intermediate stress (50 MPa) and peak stress and (b) before and after sample failure of Whitby shale sample 47B. Small changes in the first-arrival time and first-arrival amplitudes can be seen. From these data, the velocity and attenuation evolution with strain is calculated. 
fractures because relatively large amounts of energy can be absorbed by the fractures. Wave attenuation can thus be significant when traveling through a fractured medium. For S-waves traveling through the Whitby shale sample (Figure $4 \mathrm{~d}$ ), the attenuation $\left(Q^{-1}\right)$ decreases (the wave amplitude increases) in the elastic part of the deformation. This is commonly observed in stressed samples (e.g., Mavko et al., 1995; Guo et al., 2009; Zhubayev et al., 2016), and it is generally attributed to the closure of microcracks. At the transition to inelastic deformation, attenuation is increasing again and continues to increase up to peak stress conditions (the wave amplitude decreases). Here, in contrast to the ultrasonic velocity (Figure 4c), the ultrasonic attenuation (Figure 4d) exhibits a clear change in the trend at the transition from elastic to inelastic deformation. At and after peak stress conditions, when larger fractures form, a more complex attenuation pattern emerges.

We repeated these attenuation and velocity measurements during fracturing for $\mathrm{P}$ - and $\mathrm{S}$ waves for multiple Whitby shale samples (Figure 5), for porous and coarse-grained Bentheimer sandstone samples (Figure 6), and for porous Indiana limestone (Figure 7). In general, all experiments show the same behavior as described above. The transition from elastic to inelastic deformation coincides with a change from decreasing attenuation to increasing attenuation, whereas the velocity continues to increase across this boundary. The Indiana limestone samples show the same behavior (Figure 7), but the strain-attenuation curves are a bit more erratic than the ones for the shale samples. However, the lowest attenuation value still coincides with the elastic-to-inelastic transition. The Bentheimer sandstone samples show a large initial decrease in attenuation during the elastic part of the deformation (Figure 6), presumably due to the relatively large amount of microcrack closure at elevated stresses due to the high initial porosity. However, also for the Bentheimer sandstone, the lowest attenuation value coincides with the transition from elastic to inelastic deformation.

\section{DISCUSSION}

A decrease in attenuation with increasing strain and stress in the elastic regime is often observed in ultrasonic measurements on rocks (e.g., Toksoz et al., 1979; Winkler and Nur, 1979; Mavko et al., 1995; Guo et al., 2009; Wei and $\mathrm{Fu}, 2014$; Zhubayev et al., 2016), and it is attributed to the closure of preexisting microcracks. The subsequent increase in attenuation in the inelastic regime observed here for all three studied rock types confirms the observation of Couvreur et al. (2001) that an increase in attenuation can be attributed to the appearance of new brittle fractures. Here, we have shown consistently that a minimum in attenuation occurs at the onset of inelastic deformation. This means that the attenuation analysis of ultrasonic P- and S-waves can be used to determine the transition from elastic to inelastic deformation. Analysis of P- and S-wave velocity might not always show the same sensitivity to this transition.

The applied uniaxial stress preferentially results in microfractures that are parallel to the propagation direction of the transmitted ultrasonic waves (i.e., vertical in our setup). These microfractures cause dissipation of ultrasonic energy along the open fracture surfaces (Lockner et al., 1977). The P- and S-waves are attenuated; however, $\mathrm{S}$-waves are slightly more sensitive to the presence of microfractures and attenuate more than P-waves (Figure 5). At the same time, the newly formed microfractures hardly influence the ultrasonic velocity in this study (Figures 4-7). This can be qualitatively

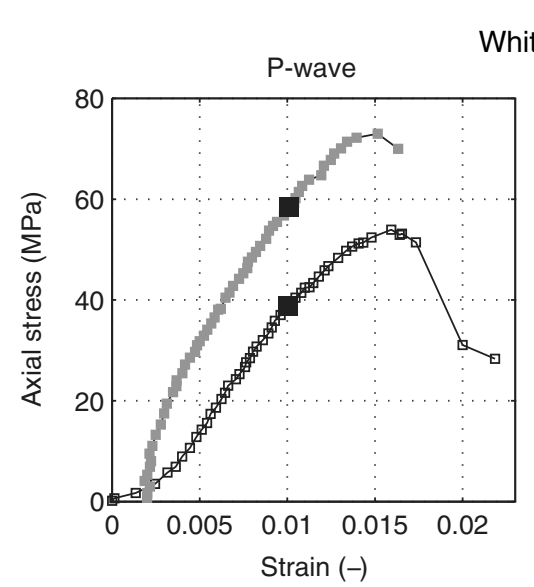

Whitby shale
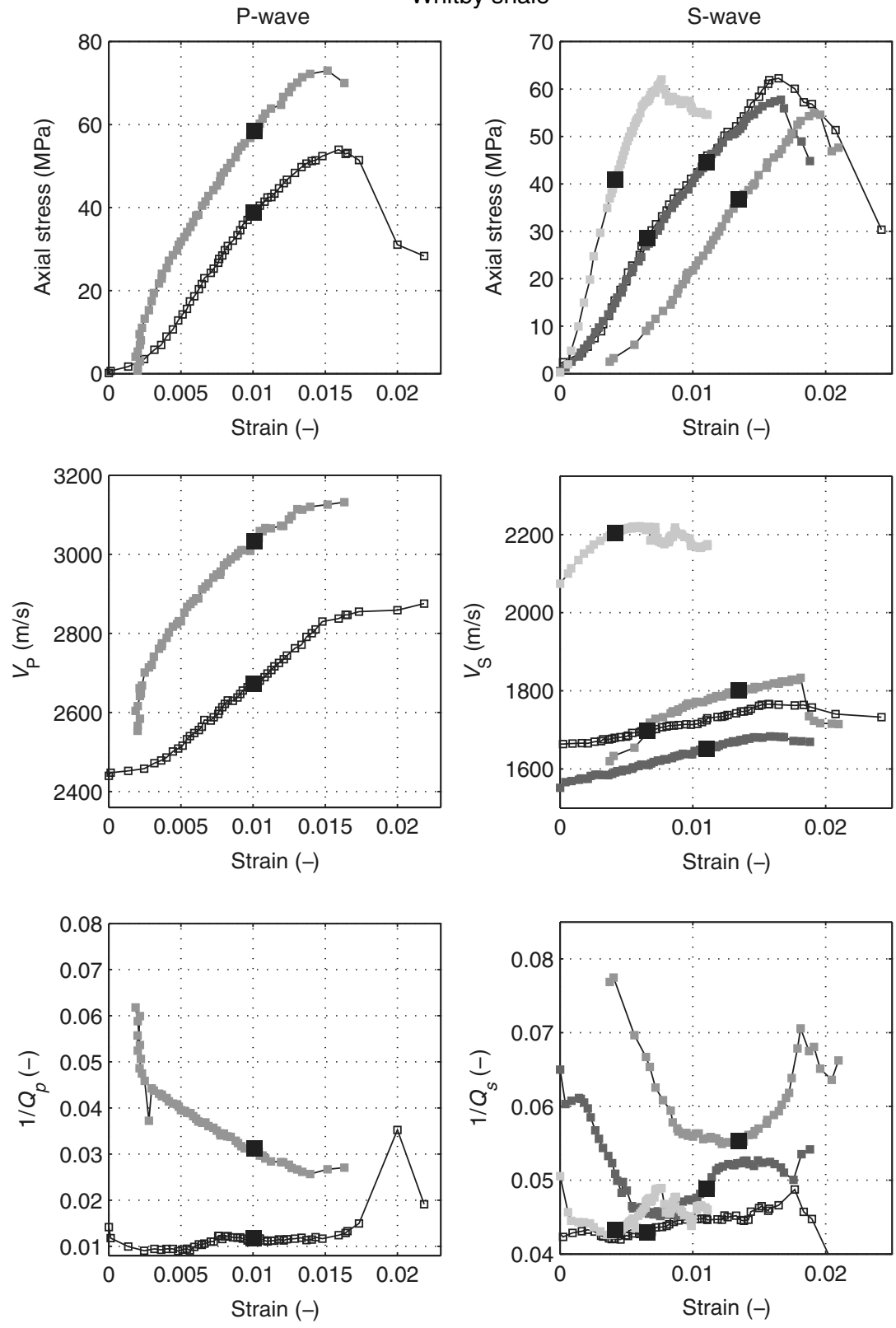

Figure 5. Axial stress-strain data, P- and S-wave velocity-strain data, and P- and S-wave attenuation-strain data for Whitby shale. The large black squares indicate the transition from elastic to inelastic deformation; different gray levels indicate different experiments. 
understood because stress-driven microfractures formed more or less parallel to the ultrasonic propagation direction (vertical in Figure 1). Those stress-driven microfractures occupy a negligible area of the sample cross section that is relevant for estimating the effective medium properties (e.g., velocity). If area averaging is applied in this propagation-perpendicular cross section (Backus, 1962), the propagation-parallel fractures almost do not contribute and the effective medium is virtually equal to the rock without these microfractures. Also, with further stress increases, the favorably oriented preexisting microfractures (mainly horizontal in Figure 1) continue to close and hence the ultrasonic velocity can continue to increase. In experimental studies in which microfractures have formed perpendicular or more oblique to the propagation direction of
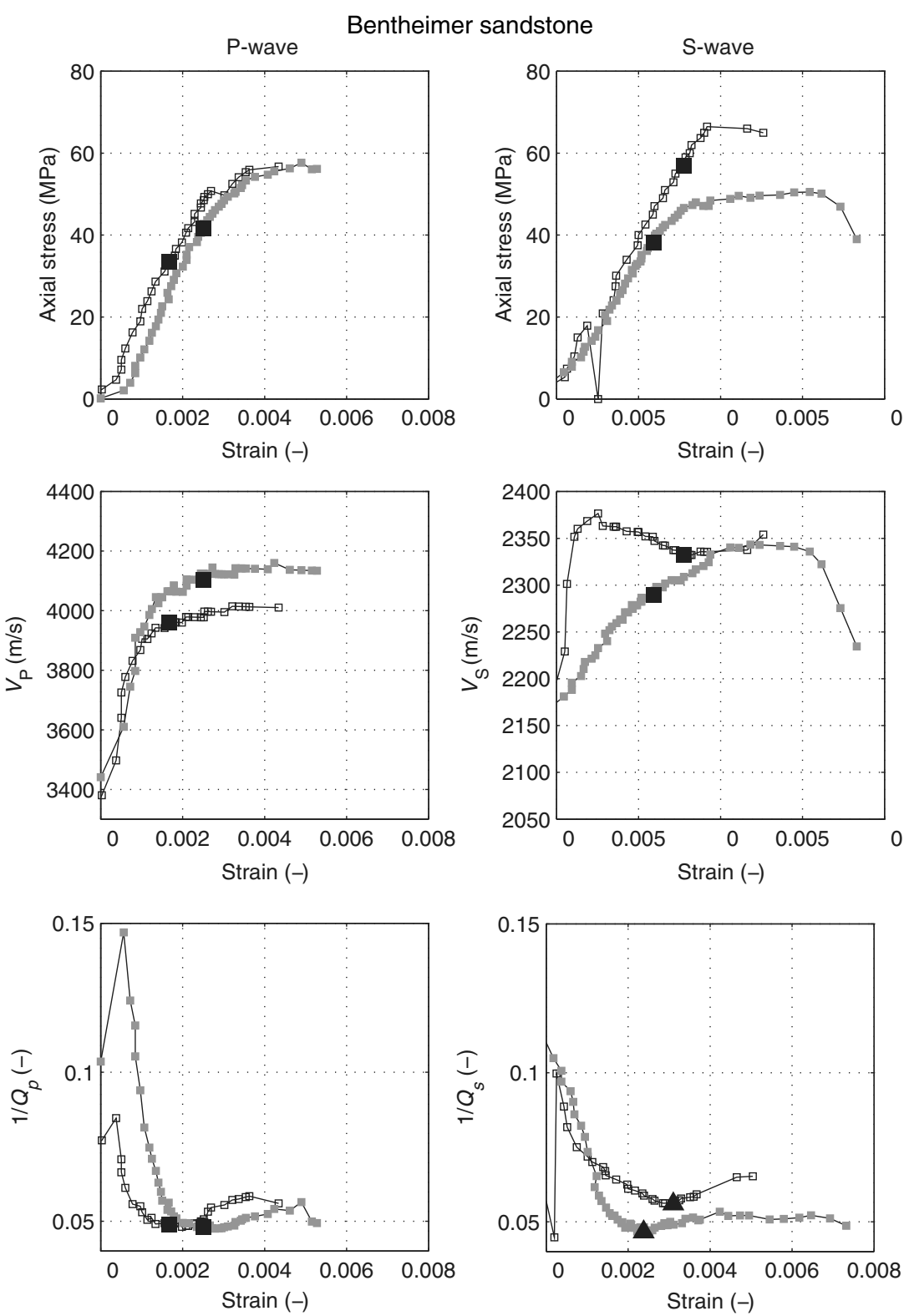

Figure 6. Axial stress-strain data, P- and S-waves velocity-strain data, and P- and Swaves attenuation-strain data for Bentheimer sandstone. The large black symbols indicate the transition from elastic to inelastic deformation; different gray levels indicate different experiments. the ultrasonic waves, and remain open after formation, these fractures may affect the velocity to such an extent that a reduction of velocity occurs at the elastic to inelastic transition. Several experimental studies have shown a reduction of velocities close to the transition from elasticity to inelasticity before failure of the sample (e.g., Ayling et al., 1995; Sarout and Guéguen, 2007; Goodfellow et al., 2015; Bonnelye et al., 2017). Some of the velocity-strain experimental curves show a reduction in velocity toward large strains, whereas other data sets do show more constant velocity values at large strains (in those studies and here). Whether the velocity is sensitive enough to the formation of the first microfractures at the transition of elasticity to inelasticity to show a clear reduction in velocity depends on several parameters such as crack density formed immediately after the transition, the preferred orientation of the fractures with respect to the main propagation direction of the ultrasonic waves, the aperture of the fractures, and possibly also of the microstructural characteristics (e.g., porosity, anisotropy) of the material. It can be concluded that velocity analyses may sometimes be sufficient to depict the transition from elasticity to inelasticity. However, as the results of this study show, the sensitivity of the attenuation of the ultrasonic waves is more sensitive to the onset of the formation of the first differential stress-driven microfractures. Therefore, attenuation/waveform analyses should at least complement the velocity analyses for the purpose of monitoring failure in rocks using ultrasonic/seismic techniques.

We performed the fracturing experiments at unconfined conditions favouring the formed fractures to remain open. High confining/radial pressures will tend to form shear fractures with very small apertures or close open fractures, thereby reducing the efficiency to attenuate seismic waves (Lockner et al., 1977). Therefore, at high confining pressures (i.e., at large depths in the subsurface), we expect the increase in attenuation in the inelastic regime due to fracturing to be less pronounced. On the contrary, higher confining pressures will cause the rock samples, particularly shales, to deform in a more semibrittle to ductile fashion and we expect fracturing to be more evenly distributed in the sample (e.g., Schueller et al., 2010). The larger amount of microfractures in such semibrittle/ductile rocks in turn may cause an increase in attenuation of the P- and S-waves. The experiments of this study are performed at high ultrasonic frequencies (a central frequency of $1 \mathrm{MHz}$ corresponding to wavelengths of a few millimeters). The aperture of the microfractures is in the order of tens of micrometers, still significantly smaller than the wavelength (approximately $2-4 \mathrm{~mm}$ ). The fractured rock samples can thus be considered an effective medium, and point scattering along individual fracture surfaces is minimal. Further research is needed to determine if the 
minimum in attenuation is also present at a large range of frequencies and with different pore-fluid contents because attenuation is highly sensitive to frequency and fluid type (Jones, 1986).

The general observation that a minimum in attenuation coincides with the transition from elastic to inelastic deformation can potentially be used as a tool to predict if a rock volume is approaching failure. Microscopic fractures form early in the loading history, causing the attenuation to increase, but they occur before the macroscopic failure of the sample. Therefore, the change in the trend of attenuation can be used to indicate that the rock has now passed its elastic limit and large-scale failure may occur soon with a continuing increase in stress. How soon this large-scale failure occurs
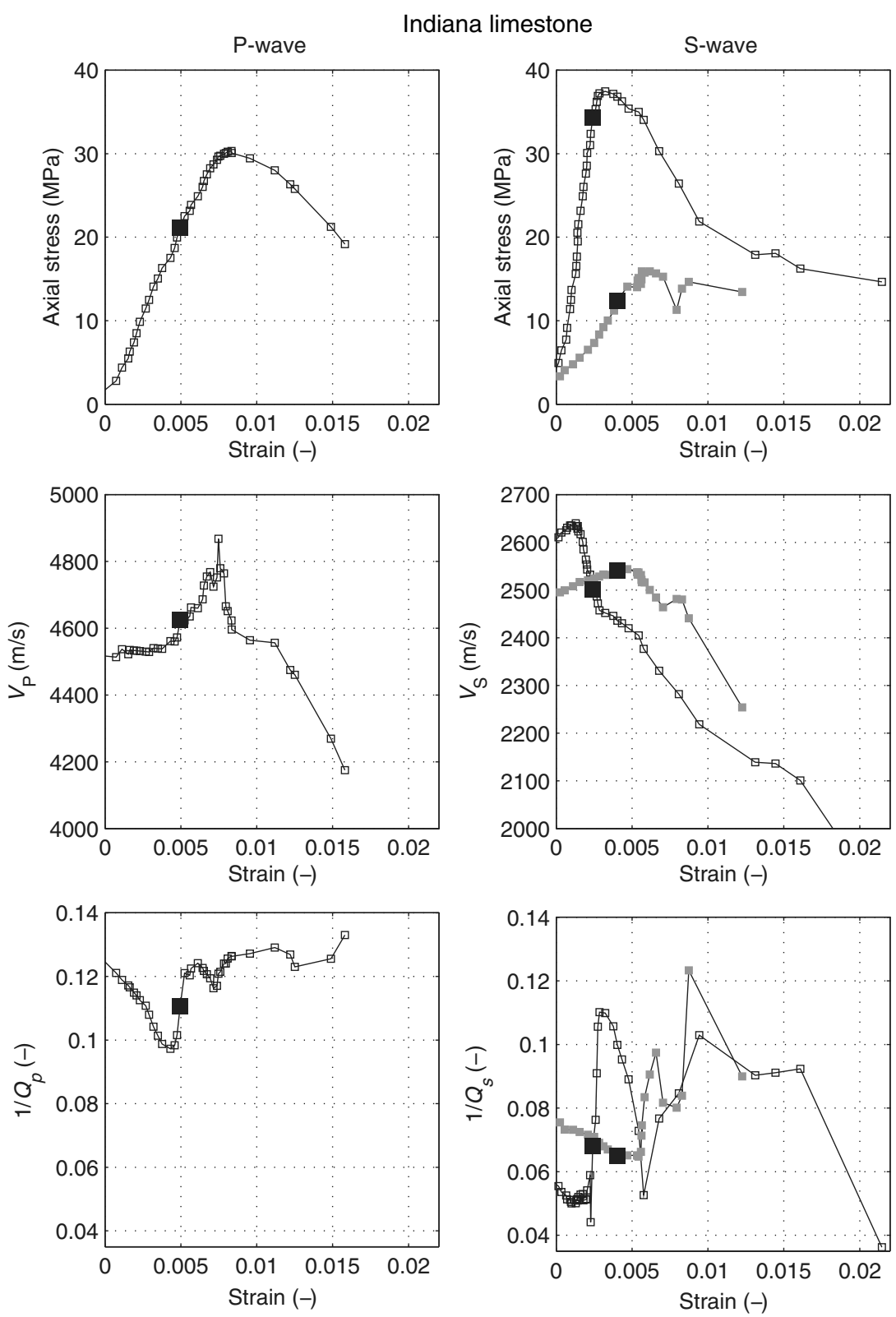

Figure 7. Axial stress-strain data, P- and S-waves velocity-strain data, and P- and Swaves attenuation-strain data for Indiana limestone. The large black squares indicate the transition from elastic to inelastic deformation; different gray levels indicate different experiments. depends on the rate of stress increase and the mechanical rock properties. Some material can withstand large amounts of plastic strain before failure (e.g., ductile materials), whereas others fail very quickly after the formation of the first microfractures (brittle, stiff materials).

This method may potentially be useful in monitoring applications of, for example, the integrity/fatigue of materials in construction sites or in the integrity of boreholes. Continuous/periodic monitoring of the change in wave amplitude transmitted through a medium may show when a large-scale failure of the material is approaching or when fracturing/damage occurs in the near-wellbore environment. If upscaling in length scales and frequency range predict similar sensitivities of the wavefield attenuation to the onset of fracturing, this method may also be used in monitoring applications of (induced) seismicity. Approaching rock failure may be picked up by analysis of the wave amplitude before the seismicity/earthquake occurs, similarly to analyzing passive microseismicity before failure. However, passive microseismic analyses have the limitation that some of the energy of the seismic events may be too low to be picked up by the microseismic array due to the attenuative nature of rocks. An active high-energy seismic technique can be adjusted to ensure the energy of the signal is sufficient to travel until the recording array. It could then be used to predict which fault structures are close to failure, and measures can be taken to prevent/minimize the effect of seismicity along that fault structure. Although the outcomes of our experimental study may have potential for these monitoring applications, further research is required to see whether the method is sensitive enough on scales and frequencies beyond the laboratory scale.

\section{CONCLUSION}

The transition from elastic to inelastic deformation in fracturing experiments coincides with a minimum in attenuation of ultrasonic waves transmitted through the rock samples. Formation of the first microfractures after yield stress conditions is thus marked by the start of the increase in attenuation. As a result, the start of attenuation increase precedes the formation of larger fractures and subsequent macroscopic failure. On the contrary, the P- and S-wave velocities during fracturing are in this study not sensitive enough to be used to identify the transition from elastic to inelastic deformation. Potentially, attenuation analysis of ultrasonic/seismic waves can be useful in monitoring applications of, for example, the integrity/fatigue of materials, borehole integrity, or near-wellbore fracturing. If attenuation changes due to fracturing could also be picked up in cross-borehole settings, a similar analysis could be used to predict when a seismic event is imminent. 


\section{ACKNOWLEDGMENTS}

Funding from the Dutch Upstream Gas top-sector initiative (project number TKIG01020) and our industry partners EBN, Engie, Wintershall is acknowledged. J. Verheij acknowledges the "Stichting Molengraaff Fonds," and M. Frechner acknowledges the Swiss National Science Foundation (SNF) project UPseis (project number 143319) for financial support. We are also indebted to K. Heller for his technical support during the experiments. The detailed and constructive reviews of C. Morency, J. Sarout, and another reviewer are acknowledged. The data sets of this manuscript are accessible via the 4TU depository: https://data.4tu.nl/repository/ uuid:f47a3eaf-7cd0-4e4a-ac48-91a293314134.

\section{REFERENCES}

Alassi, H., R. Holt, and M. Landrø, 2010, Relating 4D seismics to reservoir geomechanical changes using a discrete element approach: Geophysical Prospecting, 58, 657-668, doi: 10.1111/j.1365-2478.2009.00859.x.

Ayling, M. R., P. G. Meredith, and S. A. Murrell, 1995, Microcracking during triaxial deformation of porous rocks monitored by changes in rock physical properties. I: Elastic-wave propagation measurements on dry rocks: Tectonophysics, 245, 205-221, doi: 10.1016/0040-1951(94) 00235-2.

Backus, G. E., 1962, Long-wave elastic anisotropy produced by horizontal layering: Journal of Geophysical Research, 67, 4427-4440, doi: 10.1029/ JZ067i011p04427.

Barnhoorn, A., S. F. Cox, D. J. Robinson, and T. Senden, 2010, Stress- and fluid-driven failure during fracture array growth: Implications for coupled deformation and fluid flow in the crust: Geology, 38, 779-782, doi: 10 $.1130 / \mathrm{G} 31010.1$.

Bonnelye, A., A. Schubnel, C. David, P. Henry, Y. Guglielmi, C. Gout, A.-L. Fauchille, and P. Dick, 2017, Elastic wave velocity evolution of shales deformed under uppermost crustal conditions: Journal of Geophysical Research, 122, 130-141, doi: 10.1002/2016JB013540.

Charléty, J., N. Cuenot, C. Dorbath, and L. Dorbath, 2006, Tomographic study of the seismic velocity at the Soultz-sous-Forets EGS/HDR site: Geothermics, 35, 532-543, doi: 10.1016/j.geothermics.2006.10.002.

Couvreur, J. F., A. Vervoort, M. S. King, E. Lousberg, and J. F. Thimus, 2001, Successive cracking steps of a limestone highlighted by ultrasonic wave: Propagation Geophysical Prospecting, 49, 71-78, doi: 10.1046/j .1365-2478.2001.00242.x.

Cramer, D. D., 2008, Stimulating unconventional reservoirs: Lessons learned, successful practices, areas for improvement: Unconventional Reservoirs Conference, SPE, doi: 10.2118/114172-MS.

Curtis, J. B., 2002, Fractured shale-gas systems: AAPG Bulletin, 86, 19211938.

Douma, L. A. N. R., M. I. W. Primarini, M. E. Houben, and A. Barnhoorn, 2017, The validity of generic trends on multiple scales in rock-physical and rock-mechanical properties of the Whitby Mudstone, United Kingdom: Marine and Petroleum Geology, 84, 135-147, doi: 10.1016/j .marpetgeo.2017.03.028.

Eslami, J., D. Grgic, and D. Hoxha, 2010, Estimation of the damage of a porous limestone from continuous (P- and S-) wave velocity measurements under uniaxial loading and different hydrous conditions: Geophysical Journal International, 183, 1362-1375, doi: 10.1111/j.1365-246X .2010.04801.x.

Fortin, J., Y. Guéguen, and A. Schubnel, 2007, Effects of pore collapse and grain crushing on ultrasonic velocities and $\mathrm{V}_{\mathrm{p}} / \mathrm{V}_{\mathrm{s}}$ : Journal of Geophysical Research, 112, B08207, doi: 10.1029/2005JB004005.

Fortin, J., S. Stanchits, G. Dresen, and Y. Guéguen, 2006, Acoustic emission and velocities associated with the formation of compaction bands in sandstone: Journal of Geophysical Research, 111, B10203, doi: 10.1029/ 2005JB003854

Frehner, M., 2014, Krauklis wave initiation in fluid-filled fractures by seismic body waves: Geophysics, 79, no. 1, T27-T35, doi: 10.1190/geo20130093.1.

Frehner, M., and S. M. Schmalholz, 2010, Finite-element simulations of Stoneley guided-wave reflection and scattering at the tips of fluid-filled fractures: Geophysics, 75, no. 2, T23-T36, doi: 10.1190/1.3340361.

Ghadeer, S. G., and J. H. S. Macquaker, 2012, The role of event beds in the preservation of organic carbon in fine-grained sediments: Analyses of the sedimentological processes operating during deposition of the Whitby Mudstone formation (Toarcian, Lower Jurassic) preserved in northeast England: Marine and Petroleum Geology, 35, 309-320, doi: 10.1016/j .marpetgeo.2012.01.001.
Goodfellow, S. D., N. Tisato, M. Ghofranitabari, M. H. B. Nasseri, and R. P. Young, 2015, Attenuation properties of Fontainebleau sandstone during true-triaxial deformation using active and passive ultrasonics: Rock Mechanics and Rock Engineering, 48, 2551-2566, doi: 10.1007/s00603015-0833-8.

Granryd, L., I. C. Getting, and H. Spetzler, 1983, Path dependence of acoustic velocity and attenuation in experimentally deformed westerly granite: Geophysical Research Letters, 10, 71-74, doi: 10.1029/ GL010i001p00071.

Groenenboom, J., and J. Falk, 2000, Scattering by hydraulic fractures: Finite-difference modeling and laboratory data: Geophysics, 65, 612-622, doi: $10.1190 / 1.1444757$.

Guo, M.-Q., L.-Y. Fu, and J. Ba, 2009, Comparison of stress-associated coda attenuation and intrinsic attenuation from ultrasonic measurements: Geophysical Journal International, 178, 447-456, doi: 10.1111/j.1365-246X .2009.04159.x.

Hadley, K., 1976, Comparison of calculated and observed crack densities and seismic velocities in westerly granite: Journal of Geophysical Research, 81, 3484-3494, doi: 10.1029/JB081i020p03484.

Haering, M. O., U. Schanz, F. Ladner, and B. C. Dyer, 2008, Characterization of the Basel 1 enhanced geothermal system: Geothermics, 37, 469-495, doi: 10.1016/j.geothermics.2008.06.002.

Hart, D. J., and H. F. Wang, 1995, Laboratory measurements of a complete set of poroelastic moduli for Berea sandstone and Indiana limestone: Journal of Geophysical Research, 100, 17741-17751, doi: 10.1029/ 95JB01242.

Heap, M. J., D. R. Faulkner, P. G. Meredith, and S. Vinciguerra, 2010, Elastic moduli evolution and accompanying stress changes with increasing crack damage: Implications for stress changes around fault zones and volcanoes during deformation: Geophysical Journal International, 183, 225-236, doi: 10.1111/j.1365-246X.2010.04726.x.

Herriaz, M., and A. F. Espinosa, 1987, Coda waves: A review: Pure and Applied Geophysics, 125, 499-577, doi: 10.1007/BF00879572.

Houben, M. E., A. Barnhoorn, J. Lie-A-Fat, T. Ravestein, C. J. Peach, and M. R. Drury, 2016, Microstructural characteristics of the Whitby Mudstone Formation (UK): Marine and Petroleum Geology, 70, 185-200, doi: 10.1016/j.marpetgeo.2015.11.011.

Houben, M. E., N. J. Hardebol, A. Barnhoorn, Q. D. Boersma, A. Carone, Y. Liu, D. A. M. de Winter, C. J. Peach, and M. R. Drury, 2017, Fluid flow from matrix to fractures in Early Jurassic shales: International Journal of Coal Geology, 175, 26-39, doi: 10.1016/j.coal.2017.03.012.

Ionov, A. M., 2007, Stoneley wave generation by an incident P-wave propagating in the surrounding formation across a horizontal fluid-filled fracture: Geophysical Prospecting, 55, 71-82, doi: 10.1111/j.1365-2478.2006 .00577.x.

Jones, T. D., 1986, Pore fluids and frequency-dependent wave propagation in rocks: Geophysics, 51, 1939-1953, doi: 10.1190/1.1442050.

Kranz, R. L., 1983, Microcracks in rock: A review: Tectonophysics, 100, 449-480, doi: 10.1016/0040-1951(83)90198-1.

Littke, R., D. Leythaeuser, J. Rullkötter, and D. R. Baker, 1991, Keys to the depositional history of the Posidonia Shale (Toarcian) in the Hils Syncline, northern Germany, in R. V. Tyson and T. H. Pearson, eds., Modern and ancient continental shelf anoxia: Geological Society of London, Special Publication 58, 311-333.

Lockner, D. A., J. B. Walsh, and J. D. Byerlee, 1977, Changes in seismic velocity and attenuation during deformation of granite: Journal of Geophysical Research, 82, 5374-5378, doi: 10.1029/ JB082i033p05374.

Main, I. G., S. Peacock, and P. G. Meredith, 1990, Scattering attenuation and the fractal geometry of fracture systems: Pure and Applied Geophysics, 133, 283-304, doi: 10.1007/BF00877164

Maksimov, G. A., A. V. Derov, B. M. Kashtan, and M. Y. Lazarkov, 2011, Estimation of hydro-fracture parameters by analysis of tube waves at vertical seismic profiling: Acoustical Physics, 57, 529-541, doi: 10.1134/ S1063771011040166.

Maultzsch, S., M. Chapman, E. R. Liu, and X. Y. Li, 2003, Modeling frequency-dependent seismic anisotropy in fluid-saturated rock with aligned fractures: Implication of fracture size estimation from anisotropic measurements: Geophysical Prospecting, 51, 381-392, doi: 10.1046/j $.1365-2478.2003 .00386 . x$.

Mavko, G. M., 1979, Frictional attenuation: An inherent amplitude dependence: Journal of Geophysical Research, 84, 4769-4775, doi: 10.1029/ JB084iB09p04769.

Mavko, G., T. Mukerji, and N. Godfrey, 1995, Predicting stress-induced velocity anisotropy in rocks: Geophysics, 60, 1081-1087, doi: 10.1190/ 1.1443836

Nicolas, A., J. Fortin, J. B. Regnet, A. Dimanov, and Y. Guéguen, 2016, Brittle and semi-brittle behaviors of a carbonate rock: Influence of water and temperature: Geophysical Journal International, 206, 438-456, doi: $10.1093 / \mathrm{gji} / \mathrm{ggw} 154$

Nicolas, A., J. Fortin, J. B. Regnet, B. A. Verberne, O. Plümper, A. Dimanov, C. J. Spiers, and Y. Guéguen, 2017, Brittle and semibrittle creep of 
Tavel limestone deformed at room temperature: Journal of Geophysical Research, 122, 4436-4459, doi: 10.1002/2016JB013557.

Paterson, M. S., and T. F Wong, 2005, Experimental rock deformation The brittle field: Springer.

Peacock, S., C. McCann, J. Sothcott, and T. R. Astin, 1994, Experimental measurements of seismic attenuation in microfractured sedimentary rock: Geophysics, 59, 1342-1351, doi: 10.1190/1.1443693.

Peksa, A. E., K.-H. A. A. Wolf, and P. L. J. Zitha, 2015, Bentheimer sandstone revisited for experimental purposes: Marine and Petroleum Geology, 67, 701-719, doi: 10.1016/j.marpetgeo.2015.06.001.

Peng, Z., and Y. Ben-Zion, 2006, Temporal changes of shallow seismic velocity around the Karadere-Düzce Branch of the North Anatolian Fault and strong ground motion: Pure and Applied Geophysics, 163, 567-600, doi: 10.1007/s00024-005-0034-6.

Powell, J. H., 2010, Jurassic sedimentation in the Cleveland Basin: A review: Proceedings of the Yorkshire Geological Society, 58, 21-72, doi: 10.1144/pygs.58.1.278

Quintal, B., R. Jänicke, J. G. Rubino, H. Steeb, and K. Holliger, 2014, Sensitivity of S-wave attenuation to the connectivity of fractures in fluid-saturated rocks: Geophysics, 79, no. 5, WB15-WB24, doi: 10.1190/ geo2013-0409.1.

Rubino, J. G., L. Guarracino, T. M. Müller, and K. Holliger, 2013, Do seismic waves sense fracture connectivity?: Geophysical Research Letters, 40, 692-696, doi: 10.1002/grl.50127.

Rubino, J. G., B. Quintal, T. M. Müller, L. Guarracino, R. Jänicke, H. Steeb, and K. Holliger, 2015, Energy dissipation of P- and S-waves in fluidsaturated rocks: An overview focusing on hydraulically connected fractures: Journal of Earth Sciences, 26, 785-790, doi: 10.1007/ s12583-015-0613-0.

Saenger, E. H., and S. A. Shapiro, 2002, Effective velocities in fractured media: a numerical study using the rotated staggered finite-difference grid: Geophysical Prospecting, 50, 183-194, doi: 10.1046/j.1365-2478 2002.00309.X

Sarout, J., and Y. Guéguen, 2007, Anisotropy of elastic wave velocities in deformed shales: Part 1 - Experimental results: Geophysics, 73, no. 5, D75-D89, doi: 10.1190/1.2952744.

Sarout, J., E. Cazes, C. Delle Piane, A. Arena, and L. Esteban, 2017, Stressdependent permeability and wave dispersion in tight cracked rocks: Experimental validation of simple effective medium models: Journal of Geophysical Research Solid Earth, 122, 6180-6201, doi: 10.1002/ 2017 JB014147.

Sayers, C. M., 2002a, Fluid-dependent shear-wave splitting in fractured media: Geophysical Prospecting, 50, 393-401, doi: 10.1046/j.1365-2478 2002.00324.x

Sayers, C. M., 2002b, Stress-dependent elastic anisotropy of sandstones: Geophysical Prospecting, 50, 85-95, doi: 10.1046/j.1365-2478.2002.00289.x.
Sayers, C. M., and M. Kachanov, 1995, Microcrack-induced elastic wave anisotropy of brittle rocks: Journal of Geophysical Research, 100, 4149-4156, doi: 10.1029/94JB03134.

Schubnel, A., and Y. Guéguen, 2003, Dispersion and anisotropy of elastic waves in cracked rocks: Journal of Geophysical Research, 108, 2101, doi: 10.1029/2002JB001824.

Schueller, S., F. Gueydan, and P. Davy, 2010, Mechanics of the transition from localized to distributed fracturing in layered brittle-ductile systems: Tectonophysics, 484, 48-59, doi: 10.1016/j.tecto.2009.09.008.

Shih, P.-J. R., and M. Frehner, 2016, Laboratory evidence for Krauklis-wave resonance in fractures and implications for seismic coda wave analysis: Geophysics, 81, no. 6, T285-T293, doi: 10.1190/geo2016-0067.1

Snieder, R., A. Gret, H. Douma, and J. Scales, 2002, Coda wave interferometry for estimating nonlinear behavior in seismic velocity: Science, 295, 2253-2255, doi: 10.1126/science.1070015.

Stanchits, S., S. Vinciguerra, and G. Dresen, 2006, Ultrasonic velocities, acoustic emission characteristics and crack damage of basalt and granite Pure and Applied Geophysics, 163, 975-994, doi: 10.1007/s00024-0060059-5.

Toksoz, M., D. Johnston, and A. Timur, 1979, Attenuation of seismic waves in dry and saturated rocks: I. Laboratory measurements: Geophysics, $\mathbf{4 4}$ 681-690, doi: 10.1190/1.1440969.

Walsh, J. B., 1965, The effect of crack on the compressibility of rock: Journal of Geophysical Research, 70, 381-389, doi: 10.1029/ JZ070i002p00381.

Wei, W., and L.-Y. Fu, 2014, Monte Carlo simulation of stress-associated scattering attenuation from laboratory ultrasonic measurements: Bulletin of the Seismological Society of America, 104, 931-943, doi: 10.1785/ 0120130082 .

Winkler, K., and A. Nur, 1979, Pore fluids and seismic attenuation in rocks: Geophysical Research Letters, 6, 1-4, doi: 10.1029/GL006i001p00001.

Yukutake, H., 1989, Fracture process of granite inferred from measurements of spatial and temporal variations in velocity during triaxial deformations: Journal of Geophysical Research, 94, 15639-15651, doi: 10.1029/ JB094iB11p15639.

Zemanek, J., and I. Rudnick, 1961, Attenuation and dispersion of elastic waves in a cylindrical bar: Journal of the Acoustical Society of America, 33, 1283-1288, doi: 10.1121/1.1908417.

Zhong, X., M. Frehner, K. Kunze, and A. Zappone, 2014, A novel EBSDbased finite-element wave propagation model for investigating seismic anisotropy: Application to Finero Peridotite, Ivrea-Verbano Zone, Northern Italy: Geophysical Research Letters, 41, 7105-7114, doi: 10 1002/2014GL060490.

Zhubayev, A., M. Houben, D. Smeulders, and A. Barnhoorn, 2016, Ultrasonic velocity and attenuation anisotropy of shales (Whitby, UK): Geophysics, 81, no. 1, D45-D56, doi: 10.1190/geo2015-0211.1. 